\title{
Editorial
}

\section{Publicaciones de Univalle en cifras}

Fiderman Machuca-Martinez

Editor-Jefe

Universidad del Valle

Cali, Colombia

A continuación, se presentan las cifras de la Universidad del Valle en cuanto a publicaciones. Los datos corresponden al período 2014-2017 y se tomaron dela base de datos de WoS.

Las cifras permiten dar una mirada inicial del tipo de producción académica de la Universidad, de su fortalezas y oportunidades.

La Figura 1 muestra un esquema relativo de las principales áreas de los documentos publicados y muestra la variedad de trabajos de la Universidad y en donde se destaca la producción en el área de Zoología (12\%).

La Figura 2 muestra que la mayor parte de las publicaciones de la Universidad corresponden a revistas indexadas en Scielo (64\%) y 36 a revista de WoS. Esto implica que los grupos deben ha- cer una revisión en los índices de medición de los grupos pues las revistas tienen diferente peso de acuerdo a las bases de datos de indexación.

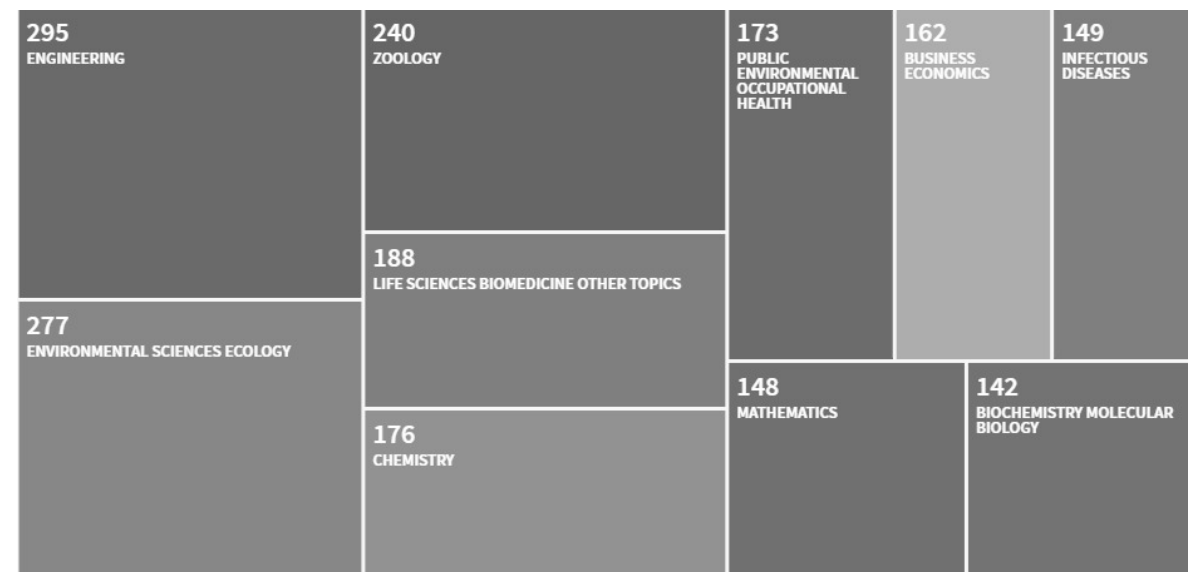

Figura 1. Principales áreas de publicación de la Universidad del Valle 2014-2017

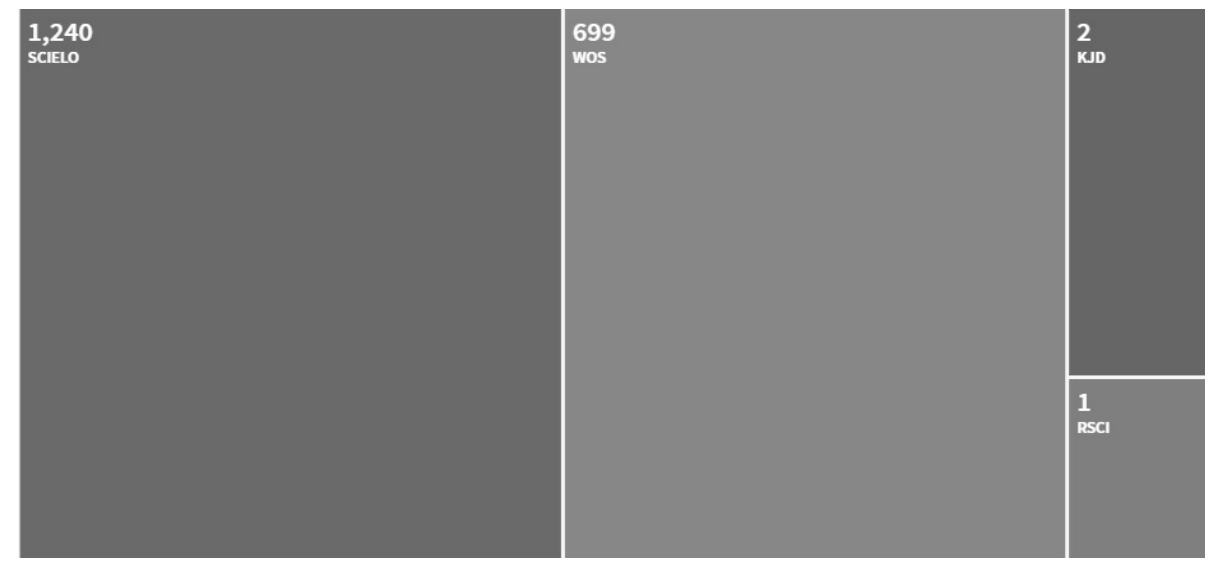

Figura 2. Distribución de revistas en bases de datos para las publicaciones de la Universidad del Valle 
Para la Universidad del Valle, se sigue manteniendo un alto porcentaje (49\%) de artículos en idioma español (Figura 3), lo cual tiene relación con las revistas indexadas de Scielo y su aporte a la difusión del conocimiento.

Por otra parte, los primeros diez países con los cuales la Univalle produjo documentos (Figura 4) muestra una fuerte relaciona con Latinoamérica, incluido Colombia y USA. Esto se relaciona con las Instituciones asociadas en las cuales las primeras siete son colombianas (figura 5). Esto se ve reflejado en las revistas donde se publica la mayor parte, las cuales corresponden a revistas nacionales (figura 6). Se puede observar la importancia de las revistas nacionales en el quehacer de la vida universitaria en donde los artículos estándar es la forma preferida de publicación, 78\% (Figura 7)
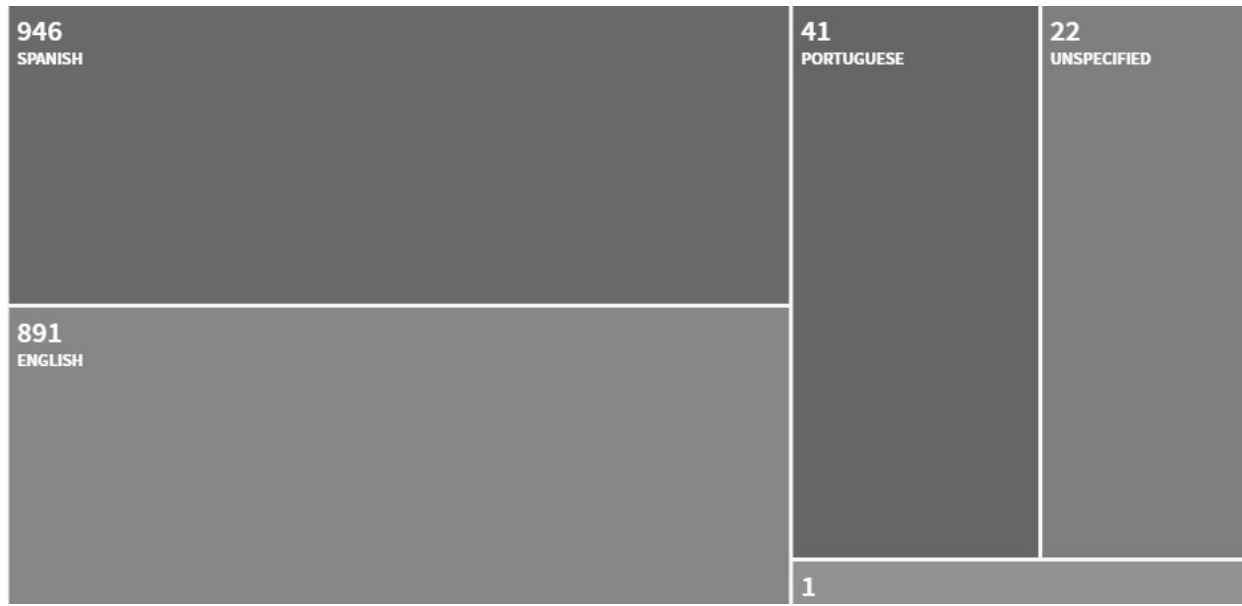

Figura 3. Distribución de idioma de publicación en la Universidad del Valle
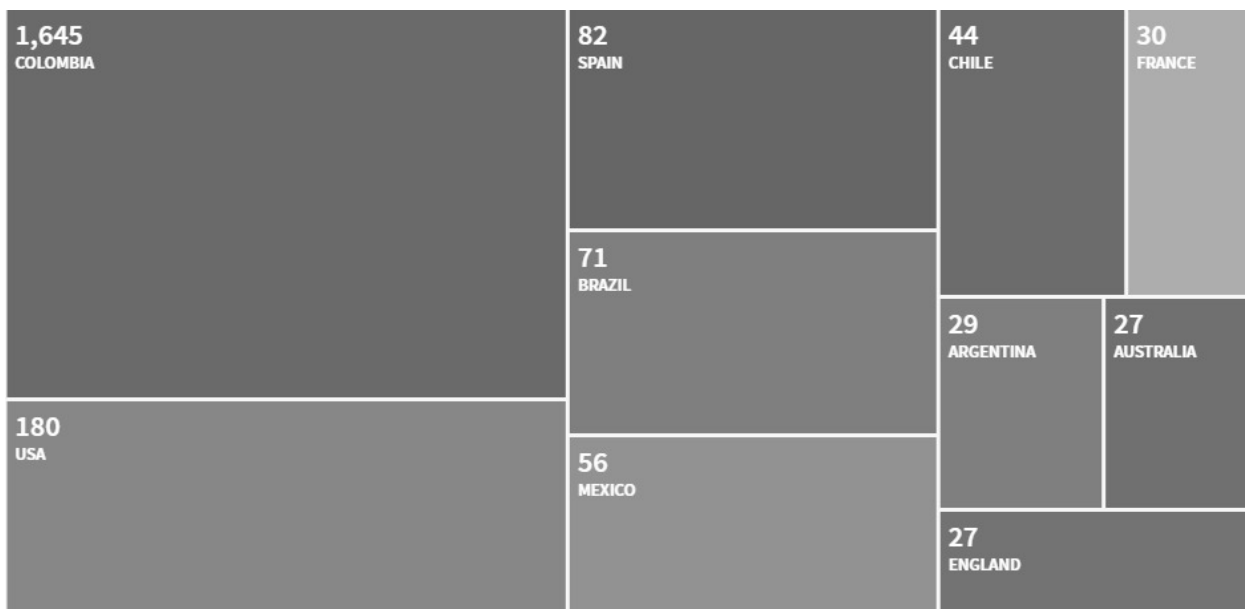

Figura 4. Relación de países que colaboran con la Universidad del Valle en las publicaciones durante 2014-2017 


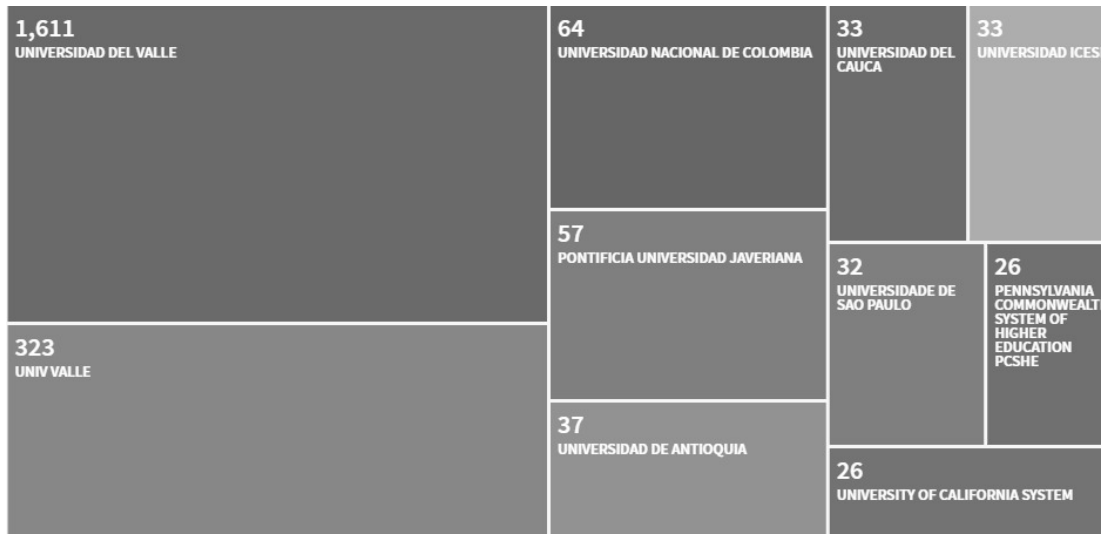

Figura 5. Distribución de instituciones colaboras en el periodo de publicación 2014-2017 entidades.

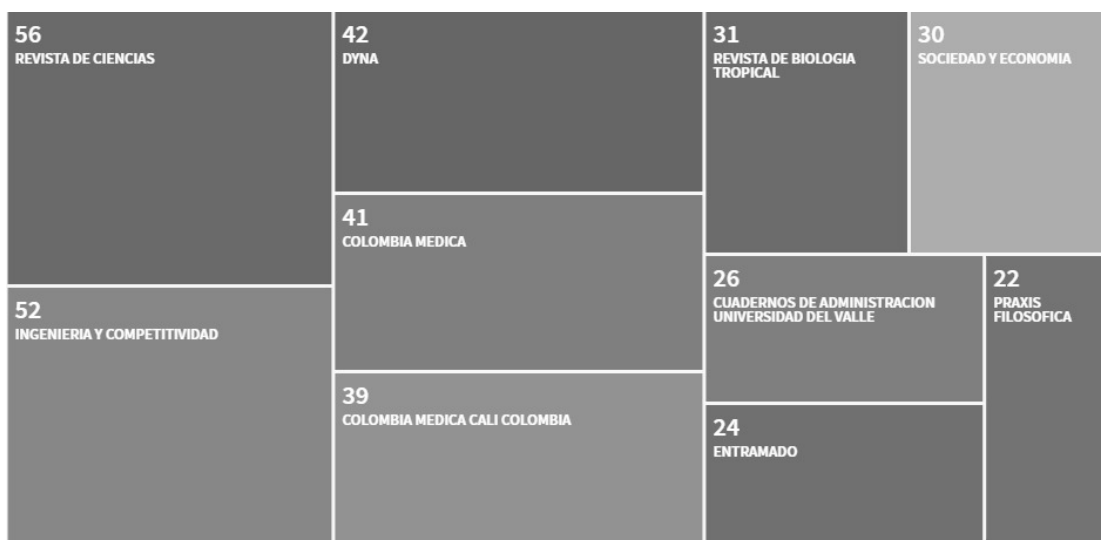

Figura 6. Primeras diez revistas donde se publicaron artículos de Univalle durante 20142017.
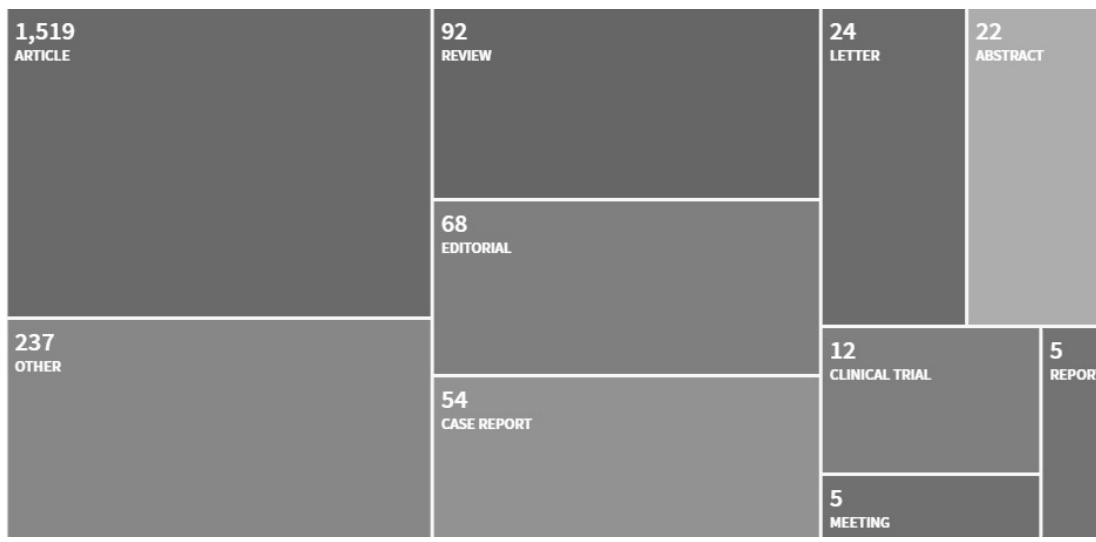

Figura 7. Tipología de publicaciones de la Universidad del Valle durante el período 20142017 